\title{
Individual Properties of the Two Functional Agonist Sites in $\mathrm{GABA}_{\mathrm{A}}$ Receptors
}

\author{
Sabine W. Baumann, Roland Baur, and Erwin Sigel \\ Department of Pharmacology, University of Bern, CH-3010 Bern, Switzerland
}

The members of the pentameric ligand-gated receptor channel family are involved in information transfer in synapses and the neuromuscular junction. They often contain several copies of the same subunit isoform. Here, we present a method to functionally dissect the role of individual subunits that occur in multiple copies in these receptors.

Opening of the inherent chloride channel in the $\mathrm{GABA}_{\mathrm{A}}$ receptor is achieved through the binding of two agonist molecules; however, it has been difficult to obtain information on the contribution of the two individual binding sites. The sites are both located at $\beta(+) / \alpha(-)$ subunit interfaces, suggesting similar properties. One pair of subunits is flanked by $\gamma$ and $\beta$ (site 1) and the other by $\alpha$ and $\gamma($ site 2 ), the different environment possibly affecting the binding sites. Here, we used concatenated subunits and two point mutations of amino acid residues, each in $\alpha$ and $\beta$ subunits, both located in the agonist binding pocket, to investigate the properties of these two sites. The sites were individually mutated, and consequences of these mutations on GABA and muscimol-induced channel opening and its competitive inhibition by bicuculline were studied. A model predicts that opening also occurs for receptors occupied with a single agonist molecule but is promoted approximately 60 -fold in those occupied by two agonists and that site 2 has an approximately threefold higher affinity for GABA than site 1, whereas muscimol and bicuculline show some preference for site 1 .

Key words: $\mathrm{GABA} ; \mathrm{GABA}_{\mathrm{A}}$ receptor; ion channel; linked subunits; agonist; bicuculline

\section{Introduction}

$\mathrm{GABA}_{\mathrm{A}}$ receptors are the major inhibitory neuronal ion channels in the mammalian brain. They belong to the family of ligandgated ion channels that includes nicotinic acetylcholine, glycine, and serotonin type 3 receptors. Biochemical purification of a bovine $\mathrm{GABA}_{\mathrm{A}}$ receptor (Sigel et al., 1983) was followed by cloning, which led to the identification of 18 different subunit isoforms (Macdonald and Olsen, 1994; Rabow et al., 1995; Davies et al., 1997; Hedblom and Kirkness, 1997; Whiting et al., 1997, 1999; Barnard et al., 1998). Most $\mathrm{GABA}_{\mathrm{A}}$ receptors are thought to be pentameric assemblies containing $\alpha, \beta$, and $\gamma$ or $\alpha, \beta$, and $\delta$ subunits (McKernan and Whiting, 1996). The five subunits are arranged pseudosymmetrically around a central $\mathrm{Cl}^{-}$-selective channel (Macdonald and Olsen, 1994). The most likely stoichiometry is two $\alpha$ subunits, two $\beta$ subunits, and one $\gamma$ or $\delta$ subunit (Backus et al., 1993; Chang et al., 1996; Tretter et al., 1997; Farrar et al., 1999; Baumann et al., 2001). The major receptor isoform of the $\mathrm{GABA}_{\mathrm{A}}$ receptor in the brain probably consists of $\alpha_{1}, \beta_{2}$, and $\gamma_{2}$ subunits (Laurie et al., 1992; Benke et al., 1994; Macdonald and Olsen, 1994; Rabow et al., 1995; McKernan and Whiting, 1996). The inferred arrangement of subunits around the channel pore is

\footnotetext{
Received May 23, 2003; revised Sept. 4, 2003; accepted 0ct. 6, 2003.

This work was supported by Swiss National Science Foundation Grant 3100-064789.01/1. We thank Dr. C. Wagner for helpful discussions on modeling, Heleen van Hees for help in preparing the linked subunit constructs, and Dr. V. Niggli for carefully reading this manuscript.

Correspondence should be addressed to Erwin Sigel, Department of Pharmacology, Friedbuehlstrasse 49, CH3010 Bern, Switzerland. E-mail: erwin.sigel@pki.unibe.ch.

Copyright $\odot 2003$ Society for Neuroscience $\quad$ 0270-6474/03/2311158-09\$15.00/0
}

$\gamma \beta \alpha \beta \alpha$ counterclockwise when viewed from the synaptic cleft (Baumann et al., 2002).

The functional GABA binding site in $\mathrm{GABA}_{\mathrm{A}}$ receptors is located at intersubunit contacts between $\alpha$ and $\beta$ subunits (Sigel et al., 1992; Amin and Weiss, 1993; Smith and Olsen, 1994; WesthHansen et al., 1997; Boileau et al., 1999), and homologous amino acid residues of $\alpha$ and $\gamma$ subunits form the benzodiazepine binding pocket (Wieland et al., 1992; Amin et al., 1997; Buhr and Sigel, 1997; Buhr et al., 1997a, b; Sigel and Buhr, 1997; Teissere and Czajkowski, 2001).

Here, we address the question of whether or not the two agonist sites on the receptor have identical properties. To our knowledge, this question has never been addressed for $\mathrm{GABA}_{\mathrm{A}}$ receptors. In the homologous nicotinic acetylcholine receptor, there is indirect evidence both for (Edelstein et al., 1997) and against (Neubig and Cohen, 1979) different properties of the agonist at the two sites. Some competitive antagonists (e.g., D-tubocurarine) differ widely in their affinity for the two sites (Martinez et al., 2000).

In the present study, we used two mutations, $\alpha_{1}$ F65L located on the minus side and $\beta_{2}$ Y205S located on the plus side, to dissect the contribution of each of the two individual functional GABA binding sites. Concatenated subunits of the $\mathrm{GABA}_{\mathrm{A}}$ receptor were used for a forced assembly. The point mutations were introduced in the $\alpha 1$ and $\beta 2$ subunits flanked by the $\gamma$ subunit and a $\beta$ subunit (site 1), by an $\alpha$ subunit and the $\gamma$ subunit (site 2), or both. Mutation of the two sites leads to subtly different consequences. 


\section{Materials and Methods}

Construction of tandem and triple subunit cDNAs. The tandem constructs, $\beta_{2}-\alpha_{1}$ and $\gamma_{2}-\beta_{2}$, and triple constructs, $\gamma_{2}-\beta_{2}-\alpha_{1}$ and $\alpha_{1}-\beta_{2}-\alpha_{1}$, were made as described previously (Baumann et al., 2001, 2002). Site-directed mutagenesis of $\alpha_{1} \mathrm{~F} 65$ to $\mathrm{L}, \beta_{2} \mathrm{Y} 62$ to $\mathrm{L}$, or $\beta_{2} \mathrm{Y} 205$ to $\mathrm{S}$ were done in the tandem constructs $\beta_{2}-\alpha_{1}$ or $\gamma_{2}-\beta_{2}$ and $\alpha_{1}-\beta_{2}$ using the QuickChange mutagenesis kit (Stratagene, Amsterdam, The Netherlands). Subsequently, the triple constructs $\gamma_{2}-\beta_{2}-\alpha_{1}$ F65L, $\gamma_{2}-\beta_{2}$ Y62L- $\alpha_{1}$, and $\alpha_{1}$ $\beta_{2}$ Y 205 S- $\alpha_{1}$ were made similar as described by Baumann et al. (2001, 2002).

Expression of linked constructs in Xenopus oocytes. Capped cRNAs were synthesized (Ambion, Lugano, Switzerland) from linearized pCMV vectors containing different tandem or triple constructs, respectively, and from the vector pVA2580 (Kuhn and Greeff, 1999) encoding a neuronal voltage-gated sodium channel. A poly-A tail of $\sim 400$ residues was added to each transcript using yeast poly-A polymerase (United States Biochemicals, Dūbendorf, Switzerland). The concentration of the cRNA was quantified on a formaldehyde gel using Radiant Red stain (Bio-Rad, Reinach, Switzerland) for visualization of the RNA and known concentrations of RNA ladder (Invitrogen, Basel, Switzerland) as standard on the same gel. cRNA combinations were precipitated in ethanol/isoamylalcohol, 19:1, and stored at $-20^{\circ} \mathrm{C}$. For injection, the alcohol was removed, and the cRNAs were dissolved in water. Isolation of oocytes from the frogs, culturing of the oocytes, injection of cRNA, and defolliculation were done as described previously (Sigel, 1987). Oocytes were injected with $50 \mathrm{nl}$ of the cRNA solution. For cRNA combinations of the triple constructs with the tandem construct, ratios of 10:10 nM were investigated. The combination of wild-type $\alpha 1, \beta 2$, and $\gamma 2$ subunits was expressed at a ratio of 10:10:50 nM (Boileau et al., 2002). To allow standardization of expressed GABA currents, cRNA coding for the voltage-gated sodium channel was always added to a concentration of $40 \mathrm{~nm}$. The injected oocytes were incubated in modified Barth's solution [10 mM HEPES, pH 7.5, $88 \mathrm{~mm} \mathrm{NaCl}, 1 \mathrm{~mm} \mathrm{KCl}, 2.4 \mathrm{~mm} \mathrm{NaHCO}, 0.82 \mathrm{~mm}$ $\mathrm{MgSO}_{4}, 0.34 \mathrm{~mm} \mathrm{Ca}\left(\mathrm{NO}_{3}\right)_{2}, 0.41 \mathrm{~mm} \mathrm{CaCl}, 100 \mathrm{U} / \mathrm{ml}$ of penicillin, 100 $\mu \mathrm{g} / \mathrm{ml}$ of streptomycin] at $18^{\circ} \mathrm{C}$ for $2 \mathrm{~d}$ before the measurements.

Two-electrode voltage-clamp measurements. All measurements were done in medium containing (in mM): $90 \mathrm{NaCl}, 1 \mathrm{MgCl}_{2}, 1 \mathrm{KCl}, 1 \mathrm{CaCl}_{2}$, and 5 HEPES, $\mathrm{pH} 7.4$, at a holding potential of $-80 \mathrm{mV}$. For the determination of maximal current amplitudes, $10 \mathrm{~mm}$ GABA (Fluka, Buchs, Switzerland) was applied for $20 \mathrm{sec}$. The perfusion solution $(6 \mathrm{ml} / \mathrm{min})$ was applied through a glass capillary with an inner diameter of $1.35 \mathrm{~mm}$, the mouth of which was placed $\sim 0.4 \mathrm{~mm}$ from the surface of the oocyte. The rate of solution change under our conditions has been estimated $70 \%$ within $<0.5 \mathrm{sec}$ (Sigel et al., 1990). Voltage-dependent sodium currents were determined by a potential jump from a holding potential of -100 to $-15 \mathrm{mV}$. Functional $\mathrm{GABA}_{\mathrm{A}}$ receptor expression was determined by application of $10 \mathrm{~mm}$ GABA. The elicited current amplitude was normalized to the Na current measured. GABA-evoked currents (at $8-12 \%$ of the maximal current amplitude) were inhibited by varying concentrations of bicuculline methiodide (Sigma/RBI, Buchs, Switzerland). Concentration-response curves for GABA were fitted with the equation $I(c)=I_{\max } /\left[1+\left(\mathrm{EC}_{50} / c\right)^{n}\right]$, where $c$ is the concentration of $\mathrm{GABA}, \mathrm{EC}_{50}$ is the concentration of GABA eliciting half-maximal current amplitude, $I_{\max }$ is the maximal current amplitude, $I$ is the current amplitude, and $n$ is the Hill coefficient. Inhibition curves for bicuculline were fitted with the equation $I(c)=I(0) /\left[1+\left(\mathrm{IC}_{50} / c\right)^{n}\right]$, where $I(0)$ is the control current in the absence of bicuculline standardized to $100 \%, I(c)$ is the relative current amplitude, $c$ is the concentration of bicuculline, $\mathrm{IC}_{50}$ is the concentration of bicuculline causing $50 \%$ inhibition of the current, and $n$ is the Hill coefficient. Data are given as mean \pm SEM (number of experiments, number of batches of oocytes). Relative current stimulation by diazepam (DZ) was determined at a GABA concentration evoking $2-5 \%$ of the maximal current amplitude in combination with varying concentrations of DZ (Roche Pharma, Reinach, Switzerland) and expressed as $\left.\left[\left(I_{(\mathrm{GABA}}+\mathrm{DZ}\right) / I_{(\mathrm{GABA})}\right)-1\right] \cdot 100$.

Western blotting. Oocytes were homogenized in lysis buffer $(10 \mathrm{~mm}$ HEPES, pH 8.0, 100 mм NaCl, 10 mм EDTA, 1\% Triton X-100, Pepstatin, Leustatin, Antipain, and PMSF, each at $5 \mu \mathrm{g} / \mathrm{ml}$ ) using a Teflon glass homogenizer. The homogenate was incubated on ice for $15 \mathrm{~min}$ and centrifuged at $15,000 \times g$ for $15 \mathrm{~min}$ at $4^{\circ} \mathrm{C}$. The supernatant was extracted with chloroform-methanol and subjected to SDS-PAGE (Laemmli, 1970). Proteins were transferred to nitrocellulose membranes (HybondECL; Amersham Pharmacia, Dūbendorf, Switzerland) according to Towbin et al. (1979) and decorated with the monoclonal antibodies bd24 and bd17 (Häring et al., 1985; Ewert et al., 1990), which recognize the $\mathrm{N}$-terminal of the $\alpha 1$ and $\beta 2$ subunits of the $\mathrm{GABA}_{\mathrm{A}}$ receptor, respectively. Bands were detected using the ECL system (Amersham Pharmacia).

Model. Because some of the parameters were in common for linked and mutated receptors, the averaged standardized data including SDs were fitted simultaneously with using a Levenberg-Marquardt algorithm (ProFit 5.1 software; ProFit, Zurich, Switzerland) in combination with the following equations: loose subunits, $I(c)=[100 \cdot(1+L)] /\left(1 /\left[1+\left(L_{1}\right.\right.\right.$ $\left.\left.\left.\cdot K_{1}\right) /\left(L_{2} \cdot K_{2}\right)+\left(L_{1} \cdot c\right) /\left(L \cdot K_{2}\right)\right]\right) \cdot\left[1+\left(K_{1} \cdot L_{1}\right) / c+L_{1}+\left(L_{1} \cdot K_{1}\right) / K_{2}+\right.$ $\left.\left(c \cdot L_{1}\right) /\left(K_{2}\right)+\left(L_{1} \cdot K_{1}\right) /\left(L_{2} \cdot K_{2}\right)+\left(c \cdot L_{1}\right) /\left(K_{2} \cdot L\right)\right]$; receptors linked $\alpha \beta \alpha / \gamma \beta, I(c)=[100 \cdot(1+f A \cdot L)] /\left(1 /\left[1+\left(L_{1} \cdot K_{1}\right) /\left(L_{2} \cdot K_{2}\right)+\left(f a \cdot L_{1}\right.\right.\right.$ $\left.\left.\cdot c) /\left(f A \cdot L \cdot K_{2}\right)\right]\right) \cdot\left[1+\left(K_{1} \cdot f a \cdot L_{1}\right) / c+f a \cdot L_{1}+\left(f a \cdot L_{1} \cdot K_{1}\right) / K_{2}+(c \cdot\right.$ $\left.\left.f a \cdot L_{1}\right) /\left(K_{2}\right)+\left(L_{1} \cdot K_{1}\right) /\left(L_{2} \cdot K_{2}\right)+\left(c \cdot f a \cdot L_{1}\right) /\left(K_{2} \cdot f A \cdot L\right)\right]$; receptors linked $\gamma \beta \alpha / \beta \alpha, I(c)=[100 \cdot(1+f G \cdot L)] /\left(1 /\left[1+\left(L_{1} \cdot K_{1}\right) /\left(L_{2} \cdot K_{2}\right)+(f g\right.\right.$ $\left.\left.\left.\cdot L_{1} \cdot c\right) /\left(f G \cdot L \cdot K_{2}\right)\right]\right) \cdot\left[1+\left(K_{1} \cdot f g \cdot L_{1}\right) / c+f g \cdot L_{1}+\left(f g \cdot L_{1} \cdot K_{1}\right) / K_{2}+\right.$ $\left.\left(c \cdot f g \cdot L_{1}\right) /\left(K_{2}\right)+\left(L 1 \cdot K_{1}\right) /\left(L_{2} \cdot K_{2}\right)+\left(c \cdot f g \cdot L_{1}\right) /\left(K_{2} \cdot f G \cdot L\right)\right] ; \alpha \beta \alpha / \gamma \beta$ receptors mutated in site 1 and an analogous equation for the mutation in residue $\alpha_{1} 65$ in site $1, I(c)=[100 \cdot(1+f A \cdot L)] /\left(1 /\left[1+\left(L_{1} \cdot K_{1} 205\right) /\right.\right.$ $\left.\left.\left(L_{2} \cdot \operatorname{ta} 205 \cdot K_{2}\right)+\left(f a \cdot L_{1} \cdot c\right) /\left(f A \cdot L \cdot \operatorname{ta} 205 \cdot K_{2}\right)\right]\right) \cdot\left[1+\left(K_{1} 205 \cdot f a \cdot L_{1}\right) / c\right.$ $+f a \cdot L 1+\left(f a \cdot L_{1} \cdot K_{1} 205\right) /\left(\operatorname{ta} 205 \cdot K_{2}\right)+\left(c \cdot f a \cdot L_{1}\right) /\left(\operatorname{ta} 205 \cdot K_{2}\right)+\left(L_{1}\right.$ $\left.\left.\cdot K_{1} 205\right) /\left(L_{2} \cdot \operatorname{ta} 205 \cdot K_{2}\right)+(f a \cdot L 1 \cdot c) /\left(f A \cdot L \cdot \operatorname{ta} 205 \cdot K_{2}\right)\right] ; \alpha \beta \alpha / \gamma \beta$ receptors mutated in site 2 and an analogous equation for the mutation in residue $\alpha_{1} 65$ in site $2, I(c)=[100 \cdot(1+f A \cdot L)] /\left(1 /\left[1+\left(L_{1} \cdot\right.\right.\right.$ ta205 $\left.\left.\left.K_{1}\right) /\left(L_{2} \cdot K_{2} 205\right)+\left(f a \cdot L_{1} \cdot c\right) /\left(f A \cdot L \cdot K_{2} 205\right)\right]\right) \cdot\left[1+\left(\operatorname{ta} 205 \cdot K_{1} \cdot f a \cdot\right.\right.$ $\left.L_{1}\right) / c+f a \cdot L_{1}+\left(f a \cdot L_{1} \cdot \operatorname{ta} 205 \cdot K_{1}\right) / K_{2} 205+\left(c \cdot f a \cdot L_{1}\right) /\left(K_{2} 205\right)+\left(L_{1}\right.$ $\cdot$ ta205 $\left.\left.\cdot K_{1}\right) /\left(L_{2} \cdot K_{2} 205\right)+\left(f a \cdot L_{1} \cdot c\right) /\left(f A \cdot L \cdot K_{2} 205\right)\right]$; and $\gamma \beta \alpha / \beta \alpha$ receptors mutated both sites, $I(c)=[100 \cdot(1+f G \cdot L)] /\left(1 /\left[1+\left(L_{1}\right.\right.\right.$. $\left.\left.\left.K_{1} 65\right) /\left(L_{2} \cdot K_{2} 65\right)+\left(f g \cdot L_{1} \cdot c\right) /\left(f G \cdot L \cdot \operatorname{ta} 65 \cdot K_{2} 65\right)\right]\right) \cdot\left[1+\left(\operatorname{ta} 65 \cdot K_{1} 65\right.\right.$ $\left.\cdot f g \cdot L_{1}\right) / c+f g \cdot L_{1}+\left(f g \cdot L_{1} \cdot K_{1} 65\right) / K_{2} 65+\left(c \cdot f g \cdot L_{1}\right) /\left(\mathrm{t} 65 \cdot K_{2} 65\right)+\left(L_{1}\right.$ $\left.\left.\left.\cdot K_{1} 65\right) /\left(L_{2} \cdot K_{2} 65\right)+\left(c \cdot f g \cdot L_{1}\right) /\left(\operatorname{ta} 65 \cdot K_{2} 65 \cdot f G \cdot L\right)\right]\right) ; I$ is the current, $K_{1}$ and $K_{2}$ are dissociation constants for agonists of the unmuted and $K_{1} 65$, $K_{2} 65, K_{1} 205$, and $K_{2} 205$ of the mutated receptors illustrated in Figure 5, $L$ describes the isomerization between the closed (ARA) and open $\left(\mathrm{ARA}^{*}\right)$ channel $\left[L=(\mathrm{ARA}) /\left(\mathrm{ARA}^{*}\right)\right], L_{1}$ and $L_{2}$ describe the isomerization between closed receptors occupied by a single agonist molecule (AR) or (RA) and the corresponding open channels $\left(\mathrm{AR}^{*}\right)$ and $\left(\mathrm{RA}^{*}\right)$, respectively, $c$ is the concentration of GABA or muscimol, $b$ is the concentration of bicuculline or SR95531, $f G$ and $f A, f g$, and $f a$ are coefficients modulating $L, L_{1}$, and $L_{2}$, respectively (gating of the channel), as a consequence of subunit linkage, and ta65 and ta205 coefficients describe the allosteric effect of the mutation in one site on the dissociation constant for GABA of the second site.

Inhibition was fitted with the equation $I(c)=I_{\max } /\left(1 /\left[1+\left(L_{1} \cdot K_{1}\right) /\right.\right.$ $\left.\left.\left(L_{2} \cdot K_{2}\right)+\left(L_{1} \cdot c\right) /\left(L \cdot K_{2}\right)\right]\right) \cdot\left[1+\left(K_{1} \cdot L_{1}\right) / c+L_{1}+\left(L_{1} \cdot K_{1}\right) / K_{2}+(c \cdot\right.$ $\left.\left.L_{1}\right) /\left(K_{2}\right)+\left(L_{1} \cdot K_{1}\right) /\left(L_{2} \cdot K_{2}\right)+\left(c \cdot L_{1}\right) /\left(K_{2} \cdot L\right)\right]+\left[\left(b \cdot K_{1} \cdot L_{1}\right) / c\right] \cdot\left[1 / K_{1 \mathrm{i}}\right.$ $\left.+1 / K_{2 \mathrm{i}}+b /\left(K_{1 \mathrm{i}} \cdot \mathrm{K}_{2 \mathrm{i}}\right)\right]$ for loose subunits, $I(c)=I_{\max } /\left[\left(1 /\left[1+\left(L_{1} \cdot\right.\right.\right.\right.$ $\left.\left.\left.K_{1} 205\right) /\left(L_{2} \cdot \operatorname{ta} 205 \cdot K_{2}\right)+\left(f a \cdot L_{1} \cdot c\right) /\left(f A \cdot L \cdot \operatorname{ta} 205 \cdot K_{2}\right)\right]\right) \cdot\left[1+\left(K_{1} 205\right.\right.$ $\left.\cdot f a \cdot L_{1}\right) / c+f a \cdot L_{1}+\left(f a \cdot L_{1} \cdot K_{1} 205\right) /\left(\operatorname{ta} 205 \cdot K_{2}\right)+\left(c \cdot f a \cdot L_{1}\right) /(\operatorname{ta} 205 \cdot$ $\left.\left.K_{2}\right)+\left(L_{1} \cdot K_{1} 205\right) /\left(L_{2} \cdot \operatorname{ta} 205 \cdot K_{2}\right)+(f a \cdot L 1 \cdot c) /\left(f A \cdot L \cdot \operatorname{ta} 205 \cdot K_{2}\right)\right]+$ $\left[\left(b \cdot K_{1} \cdot f a \cdot L_{1}\right) / c\right] \cdot\left[1 /\left(m \cdot K_{1 \mathrm{II}}\right)+1 /\left(\mathrm{tb} 205 \cdot K_{2 \mathrm{I}}\right)+b /\left(m \cdot K_{1 \mathrm{i}} \cdot\right.\right.$ tb205 $\left.\left.K_{2 \mathrm{i}}\right)\right]$ )] for $\alpha \beta \alpha / \gamma \beta$ receptors mutated in site 1, and analogously for the other receptors. $K_{1 \mathrm{i}}$ and $K_{2 \mathrm{i}}$ are dissociation constants for antagonists, $m$ is the ratio between dissociation constants of mutated divided by that of unmutated receptors, and tb65 and tb205 coefficients describe the allosteric effect of the mutation in one site on the dissociation constant for bicuculline of the second site.

\section{Results}

\section{Mutations in the agonist binding site}

We made use of the two point mutations, $\alpha_{1}$ F65L and $\beta_{2} \mathrm{Y} 205 \mathrm{~S}$, to alter agonist binding sites in recombinant $\alpha_{1} \beta_{2} \gamma_{2} \mathrm{GABA}_{\mathrm{A}}$ receptors. The first mutation has been shown previously to de- 

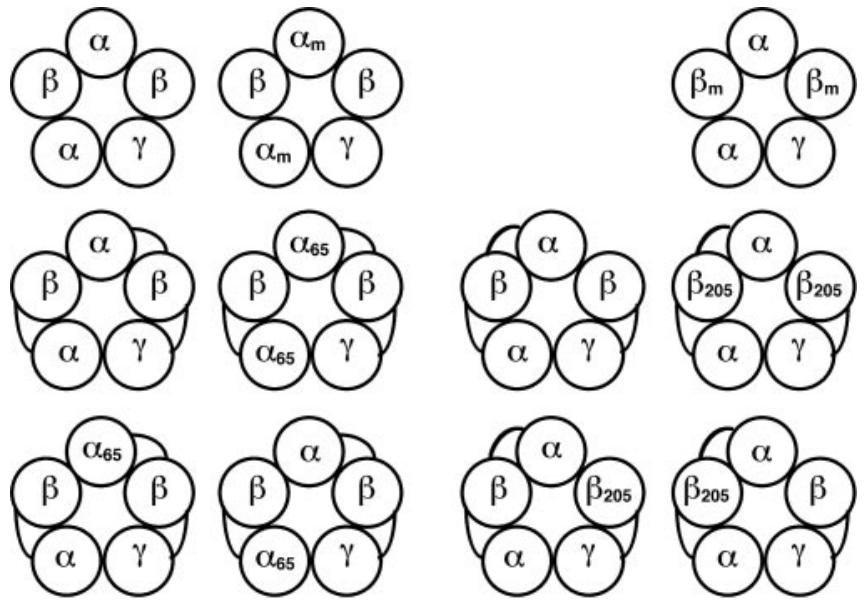

Figure 1. Mutations in $\alpha$ or $\beta$ subunits of the $\mathrm{GABA}_{\mathrm{A}}$ receptor. If a point mutation is introduced in an $\alpha$ or $\beta$ subunit, two mutations are always present in an altered receptor (top row). The availability of concatenated subunits allows construction of linked receptors containing only one mutation (bottom row). This single mutated $\alpha 1$ subunit can be placed between either two $\beta$ subunits or a $\beta$ and $\gamma$ subunit. This way, the point mutation $\alpha_{1}$ F $65 \mathrm{~L}$ has been investigated. Similarly, the mutation $\beta_{2}$ Y 2055 subunit has been investigated in a differently concatenated channel.

crease the apparent affinity of GABA for channel gating and the apparent affinity for the competitive antagonist bicuculline (Sigel et al., 1992). The mutation $\beta_{2}$ Y $205 S$ has been reported to compromise GABA binding without affecting channel opening induced by pentobarbital (Amin and Weiss, 1993). It is now known that a receptor pentamer contains two $\alpha$ and two $\beta$ subunits. Therefore, in each case, both subunits and thereby both GABA sites were affected by the point mutations in the previous studies (Fig. 1, top). We have shown previously that it is feasible to covalently link $\alpha, \beta$, and $\gamma$ subunits of the $\mathrm{GABA}_{\mathrm{A}}$ receptor while retaining full receptor function (Baumann et al., 2001, 2002). This allows the introduction of a point mutation in one individual $\alpha_{1}$ or $\beta_{2}$ subunit exclusively. Thus, the concatenated subunits $\gamma_{2}-\beta_{2}-\alpha_{1}(\gamma \beta \alpha), \beta_{2}-\alpha_{1}(\beta \alpha), \gamma_{2}-\beta_{2}-\alpha_{1}$ F65L $\left(\gamma \beta \alpha_{65}\right)$, and $\beta_{2}-$ $\alpha_{1}$ F65L $\left(\beta \alpha_{65}\right)$ were prepared and functionally expressed in $X e$ nopus oocytes as a channel containing no mutation $\gamma \beta \alpha / \beta \alpha$, one mutation $\gamma \beta \alpha_{65} / \beta \alpha$ and $\gamma \beta \alpha / \beta \alpha_{65}$, or two mutations $\gamma \beta \alpha_{65} /$ $\beta \alpha_{65}$ (Fig. 1). $\gamma_{2}-\beta_{2}$ Y62L- $\alpha_{1}\left(\gamma \beta_{62} \alpha\right)$ and $\beta_{2}$ Y62L- $\alpha_{1}\left(\beta_{62} \alpha\right)$ were also prepared for control purposes. To study a second contact point of agonists with the receptor and a differently concatenated channel, we similarly prepared $\gamma_{2}-\beta_{2}(\gamma \beta), \gamma_{2}-\beta_{2} \mathrm{Y} 205 \mathrm{~S}\left(\gamma \beta_{205}\right)$, $\alpha_{1}-\beta_{2}-\alpha_{1} \quad(\alpha \beta \alpha)$, and $\alpha_{1}-\beta_{2}$ Y $205 S-\alpha_{1} \quad\left(\alpha \beta_{205} \alpha\right) . \alpha \beta \alpha / \gamma \beta$, $\alpha \beta_{205} \alpha / \gamma \beta_{205}, \alpha \beta_{205} \alpha / \gamma \beta$, and $\alpha \beta \alpha / \gamma \beta_{205}$ (Fig. 1) were expressed in Xenopus oocytes and functionally characterized.

\section{Nonlinked receptors and linked receptors}

Linked subunits might be proteolysed during expression. If the linker region(s) specifically would be affected, nonlinked subunits could be produced from dual constructs and nonlinked subunits and dual subunit constructs could be produced from triple constructs, all products carrying part of the corresponding linkers. Such an event would complicate interpretation of the results in the event that the newly liberated subunits retain the ability to reassemble to form functional channels. Because the assembly of multi-subunit proteins is taking place in an early phase after translation in the endoplasmic reticulum, this hypothetical process would have to take place there. Figure $2 A$ shows a Western blot analysis of noninjected oocytes (lane 1), oocytes
A B

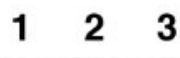

123

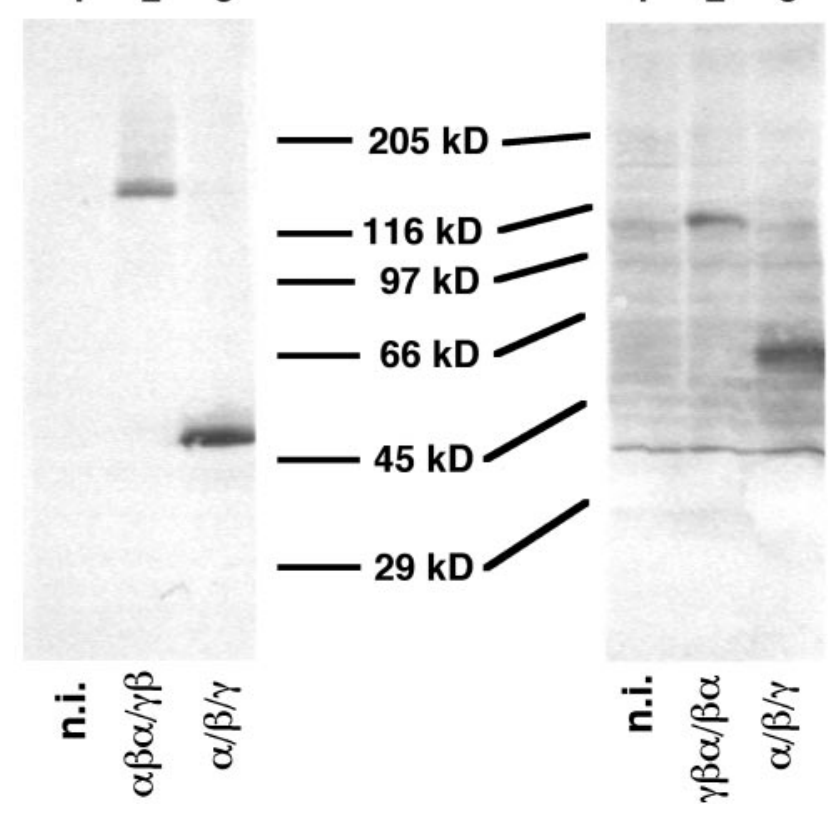

Figure 2. Western blot analysis. A, Resistance to proteolysis of the fusion protein $\alpha \beta \alpha$. Lanes 1-3 were decorated with bd24, reacting with free termini of $\alpha$ subunits. Lane 1, Noninjected oocytes (n.i.). No signal was detected in noninjected oocytes. Lane 2, 0ocytes injected with $\alpha \beta \alpha / \gamma \beta$. The $\alpha \beta \alpha$ triple construct migrates at $170 \mathrm{kDa}$. No specific signal was detected at $\sim 50$ or $110 \mathrm{kDa}$, the size of a monomeric $\alpha 1$ subunit or dimeric subunit carrying $\alpha 1$ at the $\mathrm{N}$-terminus, as expected as a consequence of proteolysis in one of the linker regions. The absence of specific signals in other areas indicates that no $\mathrm{N}$-terminal breakdown product of this triple subunit construct larger than $21 \mathrm{kDa}$ is formed. Lane 3, 0ocytes injected with $\alpha / \beta / \gamma$. The two loose $\alpha 1$ subunits from the wild-type $\alpha 1 \beta 2 \gamma 2$ receptor migrate at $\sim 50 \mathrm{kDa}$. $B$, Lanes $1-3$ were decorated with bd17 and reacted with free termini of $\beta$ subunits. Lane 1, Noninjected 0ocytes. Lane 2, 0 ocytes injected with $\gamma \beta \alpha / \beta \alpha$. The $\beta \alpha$ dual construct migrates at $\sim 110$ $\mathrm{kDa}$. No specific signal was detected at $53 \mathrm{kDa}$, the size of a monomeric $\beta 2$ subunit, as expected during proteolysis in the linker region. Lane 3, 0ocytes injected with $\alpha / \beta / \gamma$. The two loose $\beta 2$ subunits from the wild-type $\alpha 1 \beta 2 \gamma 2$ receptor migrate at $\sim 53 \mathrm{kDa}$.

expressing loose subunits $\alpha / \beta / \gamma$ (lane 3), or the combination of concatenated subunits $\alpha \beta \alpha / \gamma \beta$ (lane 2). All lanes were decorated with the $\alpha 1$-specific antibody bd24. As expected for the case of absent proteolysis, we detected no band in lane 1, a single specific band at $\sim 50 \mathrm{kDa}$ in lane 3 , and a single specific band at $\sim 170 \mathrm{kDa}$ in lane 2. Different exposures allowed an estimate of the detection limit, which was $\sim 2 \%$ for a single proteolyzed fragment. Thus, our results obtained with $\alpha \beta \alpha / \gamma \beta$ and its mutational variants (see below) cannot be explained by proteolysis and subsequent reassembly. Figure $2 B$ shows a similar analysis for oocytes injected with $\gamma \beta \alpha / \beta \alpha$ and decorated with bd17, which recognizes free $\mathrm{N}$-termini of $\beta$ subunits. In this case, a stronger nonspecific reaction occurred. However, the band corresponding to $\beta \alpha$ is clearly seen at $\sim 110 \mathrm{kDa}$. A similar analysis using antibodies directed against loops of $\alpha$ and $\beta$ and the N-terminal of $\gamma$ subunits failed because of small amounts of antigens formed in the Xenopus oocyte that were not detected with the corresponding antibodies (data not shown).

Apart from these observations, we believe it for several reasons unlikely that proteolysis of subunits is followed by assembly of the fragments to form functional channels. First, we did not obtain functional channels when we chose the linker too short. Second, we tried to functionally express a huge variety of combi- 
Table 1. Agonist and antagonist properties of wild-type, concatenated, and mutated receptors

\begin{tabular}{|c|c|c|c|c|c|c|c|c|c|}
\hline Receptor & $\begin{array}{l}\mathrm{EC}_{50}(\mathrm{GABA}) \\
(\mu \mathrm{m})\end{array}$ & Hill coefficient & $n$ & $\begin{array}{l}\mathrm{EC}_{50} \text { (muscimol) } \\
(\mu \mathrm{M})\end{array}$ & Hill coefficient & $n$ & $\begin{array}{l}\mathrm{IC}_{50} \text { (bicuculline) } \\
(\mu \mathrm{M})\end{array}$ & Hill coefficient & $n$ \\
\hline$\alpha / \beta / \gamma$ & $55 \pm 14$ & $1.4 \pm 0.1$ & 7 & $5.4 \pm 0.8$ & $1.1 \pm 0.1$ & 3 & $1.2 \pm 0.1$ & $-1.2 \pm 0.1$ & 4 \\
\hline$\gamma \beta \alpha / \beta \alpha$ & $184 \pm 14$ & $1.3 \pm 0.1$ & 6 & $24 \pm 1$ & $1.6 \pm 0.1$ & 3 & $2.0 \pm 0.3$ & $-1.3 \pm 0.1$ & 5 \\
\hline$\alpha \beta \alpha / \gamma \beta$ & $113 \pm 6$ & $1.5 \pm 0.1$ & 5 & $15.7 \pm 1.0$ & $1.6 \pm 0.1$ & 3 & $1.2 \pm 0.1$ & $-1.2 \pm 0.1$ & 5 \\
\hline$\gamma \beta \alpha_{65} / \beta \alpha$ & $1001 \pm 217$ & $1.1 \pm 0.1$ & 4 & & & & $16.5 \pm 3.9$ & $-1.1 \pm 0.1$ & 4 \\
\hline$\gamma \beta \alpha / \beta \alpha_{65}$ & $972 \pm 187$ & $1.3 \pm 0.1$ & 4 & & & & $7.4 \pm 0.7$ & $-1.0 \pm 0.1$ & 4 \\
\hline$\gamma \beta \alpha_{65} / \beta \alpha_{65}$ & $2253 \pm 703$ & $1.4 \pm 0.2$ & 4 & $94 \pm 41$ & $1.5 \pm 0.3$ & 3 & $113 \pm 27$ & $-0.7 \pm 0.1$ & 4 \\
\hline$\gamma \beta_{62} \alpha / \beta_{62} \alpha$ & $316 \pm 62$ & $1.3 \pm 0.1$ & 4 & & & & $2.0 \pm 0.5$ & $-1.1 \pm 0.1$ & 3 \\
\hline$\alpha \beta \alpha / \gamma \beta_{205}$ & $382 \pm 97^{a}$ & $1.0^{\mathrm{a}}$ & 5 & $78 \pm 9^{a}$ & $1.0^{a}$ & 4 & $10.0 \pm 1.1^{a}$ & $-1.0 \pm 0.1^{a}$ & 4 \\
\hline$\alpha \beta_{205} \alpha / \gamma \beta$ & $921 \pm 227^{a}$ & $1.0^{\mathrm{a}}$ & 6 & $37 \pm 4^{\mathrm{a}}$ & $1.0^{a}$ & 4 & $6.9 \pm 0.8^{a}$ & $-1.0 \pm 0.1^{a}$ & 4 \\
\hline
\end{tabular}

${ }^{a} \mathrm{~A}$ two-component fit was applied with a Hill coefficient of 1.0 each. Data on the first component are given. The second component gave an $\mathrm{EC}_{50}$ of $0.8 \mathrm{~m}$ for $\alpha \beta \alpha / \gamma \beta_{205}$ and $10 \mathrm{~m}$ for $\alpha \beta_{205} \alpha / \gamma \beta$.

nations of dual and triple constructs without succeeding unless a channel $\gamma \beta \alpha \beta \alpha$ could be formed directly (Baumann et al., 2001, 2002). If proteolysis would lead to functional channels, many of the non- $\gamma \beta \alpha \beta \alpha$ channels should have resulted in functional expression. Specifically, we expressed $\beta \alpha$ alone (Baumann et al., 2001 ) and $\gamma \beta \alpha$ in combination with $\alpha$ or $\beta$ subunits (Baumann et al., 2002) and observed very little, if any, current. Third, the hypothetical proteolysis leading to different functional channels than envisaged would be predicted to lead to a channel mixture. We never observed evidence for a two or more phasic doseresponse curve for nonmutated channels.

At a functional level, the effect of subunit concatenation was first studied. Thus, the functional properties of nonlinked receptors, $\alpha / \beta / \gamma$, and linked receptors, $\alpha \beta \alpha / \gamma \beta$ and $\gamma \beta \alpha / \beta \alpha$, were compared. Concentration-response curves for GABA and muscimol, as agonists, and inhibition of currents elicited by GABA by bicuculline were measured for all three types of receptors. Results are summarized in Table 1 . Subunit concatenation resulted in a 2- to 3.5-fold loss in agonist sensitivity. In contrast, subunit concatenation did not significantly affect the $\mathrm{IC}_{50}$ for bicuculline in $\alpha \beta \alpha / \gamma \beta$ receptors and only to a very small extent in $\gamma \beta \alpha / \beta \alpha$ receptors.

\section{Effect of the mutation $\alpha_{1}$ F65L on agonist} concentration-response properties for GABA and muscimol Figure $3 A$ summarizes average concentration-reponse curves for wild-type $\gamma \beta \alpha / \beta \alpha$ and mutant $\gamma \beta \alpha_{65} / \beta \alpha_{65}$ channels and also shows curves derived from channels harboring a single mutation $\gamma \beta \alpha_{65} / \beta \alpha$ and $\gamma \beta \alpha / \beta \alpha_{65}$. The curves obtained from the channels containing one mutation displayed properties more similar to channels with two mutated sites. Data are summarized in Table 1.

GABA concentration-response curves were also obtained for mutant $\gamma \beta_{62} \alpha / \beta_{62} \alpha$ channels (data are given in Table 1). $\beta_{62}$ is the homologous residue in the $\beta_{2}$ subunit to $\alpha_{65}$ in the $\alpha_{1}$ subunit and has been proposed to contribute to high-affinity binding of agonists (Newell et al., 2000). The mutation introduced in both $\beta_{2}$ subunits had only a very small effect on $\mathrm{EC}_{50}$. Each of the channels harboring a single mutated subunit was studied only twice. As expected, an intermediate $\mathrm{EC}_{50}$ resulted (data not shown).

The concentration-response curves for the agonist muscimol was also performed with wild-type $\gamma \beta \alpha / \beta \alpha$ and mutant $\gamma \beta \alpha_{65}$ / $\beta \alpha_{65}$ channels (Fig. 3B). Quantitative data are given in Table 1. Although double mutation caused a 12-fold shift in the $\mathrm{EC}_{50}$ for GABA, it amounted to only fourfold for muscimol.

\section{Effect of the mutation $\beta_{2}$ Y205S on agonist concentration-} response properties for GABA and muscimol

Figure $4 A$ illustrates concentration-response curves obtained from wild-type $\alpha \beta \alpha / \gamma \beta$ channels with GABA and muscimol, re- spectively (values are given in Table 1). The channel containing two mutations did not result in any detectable current for GABA concentrations up to $10 \mathrm{~mm}$. At $100 \mathrm{~mm}$, the elicited current amounted to $0.1 \%$ of the maximal current amplitude of wild-type $\alpha \beta \alpha / \gamma \beta$ channels. Expression of all channels was verified by determining the amplitude of the coexpessed voltage-gated Na channel and using direct activation of the GABA channel by $1 \mathrm{~mm}$ pentobarbital. The observed current amplitudes elicited by pentobarbital were in the range of 200-1200 nA for the wild-type channel (10 oocytes), 300-2800 nA for the $\alpha \beta \alpha / \gamma \beta_{205}$ channel (13 oocytes), $70-400 \mathrm{nA}$ for $\alpha \beta_{205} \alpha / \gamma \beta$ channels (14 oocytes), and 2-60 nA for $\alpha \beta_{205} \alpha / \gamma \beta_{205}$ channels (15 oocytes). The reasons for the small currents in the latter case is not known; however, because the corresponding oocytes expressed microampere-sized Na currents, it cannot be explained by either failure of injection or presence of RNase activity in the injection solution.

The mutation $\beta_{2}$ Y205S destroys the agonist binding site and theoretically should uncover the properties of the second site. Thus, in $\alpha \beta_{205} \alpha / \gamma \beta$ mutant receptors, only site 1 should be visible and in $\alpha \beta \alpha / \gamma \beta_{205}$ mutant receptors, only site 2 should be visible. The maximal current amplitudes of $\alpha \beta_{205} \alpha / \gamma \beta$ and $\alpha \beta \alpha /$ $\gamma \beta_{205}$ mutant receptors could not be determined because the affinity of the second site is in the molar range. For evaluation of data, it was assumed that this parameter was the same as for $\alpha \beta \alpha / \gamma \beta$ channels. Figure $4 B$ summarizes the dose-response curves in response to the agonists GABA and muscimol on $\alpha \beta_{205} \alpha / \gamma \beta$ and $\alpha \beta \alpha / \gamma \beta_{205}$ mutant receptors after normalization to the maximal current amplitude of unmutated $\alpha \beta \alpha / \gamma \beta$ receptors. All average curves were fitted with a two component logistic equation (Fig. $4 B$, solid lines). Data are summarized in Table 1. The absolute amplitudes should be judged with care because they depend on the expression rate. Our observations are in line with a preference of site 2 for GABA and a preference of site 1 for muscimol. It was interesting to see whether the assumption that $\alpha \beta_{205} \alpha / \gamma \beta$ and $\alpha \beta \alpha / \gamma \beta_{205}$ mutant receptors display the same maximal current amplitudes as $\alpha \beta \alpha / \gamma \beta$ receptors affected our basic findings. Therefore, three different alternative possibilities were tested. First, it was assumed that the maximal currents by both mutant receptors were only one-fifth of the standardized currents. Second, it was assumed that they were both five times the standardized currents and, third, that $\alpha \beta \alpha / \gamma \beta_{205}$ and $\alpha \beta_{205} \alpha / \gamma \beta$ mutant receptors had a twofold, respectively onethird, maximal current amplitude of wild-type receptors, as suggested by the currents elicited by $1 \mathrm{~mm}$ pentobarbital. Our basic conclusions were not affected in any of the three cases.

\section{Inhibition by bicuculline}

The concentration-dependent inhibition of GABA-induced currents by the competitive antagonist bicuculline was also studied. 

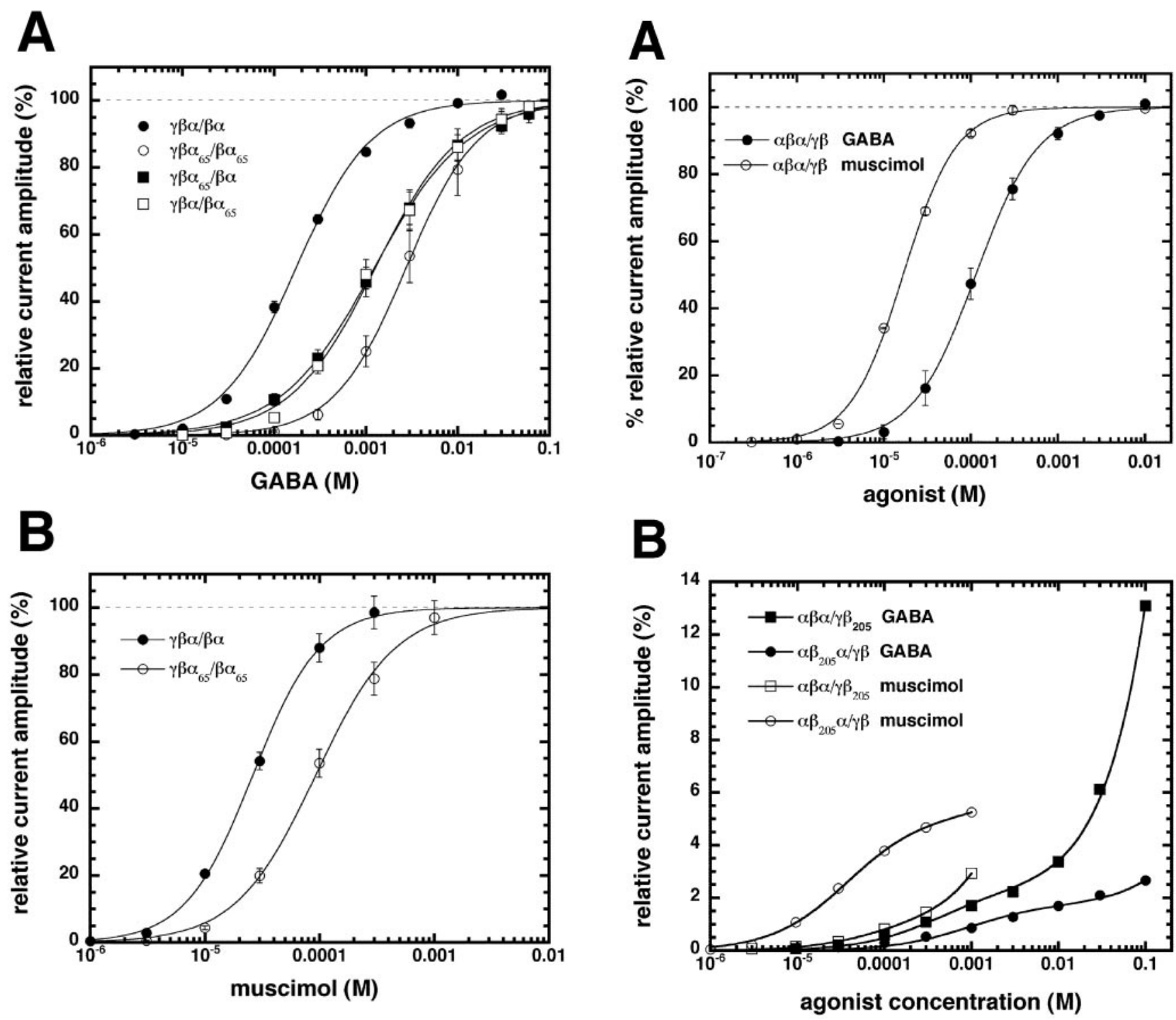

Figure 3. $A$, GABA concentration-response curves of $\gamma \beta \alpha / \beta \alpha(-), \gamma \beta \alpha_{65} / \beta \alpha_{65}(\bigcirc)$, $\gamma \beta \alpha_{65} / \beta \alpha(\square)$, and $\gamma \beta \alpha / \beta \alpha_{65}(\square)$ receptors. B, Muscimol concentration-response curves of $\gamma \beta \alpha / \beta \alpha(O)$ and $\gamma \beta \alpha_{65} / \beta \alpha_{65}(\bigcirc)$ receptors. Mean values with SEM from four to five oocytes from two batches for each subunit combination are shown. Individual curves were first normalized to the observed maximal current amplitude and subsequently averaged.

Opening of the GABA receptor channel was standardized by performing experiments approximately at the respective $\mathrm{EC}_{10}$ $\left(\mathrm{EC}_{8.9}-\mathrm{EC}_{11.2}\right)$, except for the receptors containing a $\beta_{2} \mathrm{Y} 205 \mathrm{~S}$ mutation. For the mutant $\gamma \beta \alpha_{65} / \beta \alpha_{65}$ channels, as compared with wild-type $\gamma \beta \alpha / \beta \alpha$ channels, $\mathrm{IC}_{50}$ for the competitive antagonist bicuculline is shifted to 56-fold higher concentrations. Figure $5 A$ summarizes these experiments and, in addition, shows average curves obtained with channels harboring a single mutation, $\gamma \beta \alpha_{65} / \beta \alpha$ and $\gamma \beta \alpha / \beta \alpha_{65}$, which were shifted eightfold and fourfold, respectively. Quantitative data are summarized in Table 1.

Bicuculline concentration-inhibition curves were also obtained from mutant $\gamma \beta_{62} \alpha / \beta_{62} \alpha$ channels (Table 1). The mutation introduced in both $\beta_{2}$ subunits had no significant effect. Therefore, channels harboring a single mutated subunit were not studied.

Figure $5 B$ summarizes bicuculline inhibition curves for wildtype $\alpha \beta \alpha / \gamma \beta$ and single mutant $\alpha \beta_{205} \alpha / \gamma \beta$ and $\alpha \beta \alpha / \gamma \beta_{205}$ channels, respectively. Both curves of mutant receptors would be ex-

Figure 4. $\quad A, G A B A(\bigcirc)$ and muscimol $(\bigcirc)$ concentration-response curves of $\alpha \beta \alpha / \gamma \beta$ receptors. $B, G A B A$ (closed symbols) and muscimol (open symbols) concentration-response curves of $\alpha \beta \alpha / \gamma \beta_{205}$ (square symbols) and $\alpha \beta_{205} \alpha / \gamma \beta$ (round symbols) receptors. Mean values with SEM from four to five oocytes from two batches for each subunit combination are shown. For receptors containing no mutation, individual curves were first normalized to the observed maximal current amplitude and subsequently averaged. For mutated receptors, amplitudes were normalized to the average maximal response elicited by GABA in $\alpha \beta \alpha / \gamma \beta$ receptors.

pected to superimpose with those of concatenated wild-type receptors, unless the effects of mutations were allosterically communicated to the other site. Because the shift amounts to approximately sevenfold in both cases, this seems to be the case. Quantitative data are summarized in Table 1. Inhibition for $\alpha \beta \alpha / \gamma \beta_{205}$ and $\alpha \beta_{205} \alpha / \gamma \beta$ receptors was measured at a GABA concentration of 100 and $300 \mu \mathrm{M}$, respectively.

\section{Inhibition by SR95531}

Inhibition by the competitive inhibitor SR95531 was determined for $\gamma \beta \alpha / \beta \alpha, \gamma \beta \alpha_{65} / \beta \alpha, \gamma \beta \alpha / \beta \alpha_{65}, \gamma \beta \alpha_{65} / \beta \alpha_{65}, \alpha \beta \alpha / \gamma \beta$, $\alpha \beta_{205} \alpha / \gamma \beta$, and $\alpha \beta \alpha / \gamma \beta_{205}$ under conditions described for bicuculline. In all cases, a qualitatively similar behavior was found. The respective $\mathrm{IC}_{50}$ were $\sim 10$-fold lower than with bicuculline. 


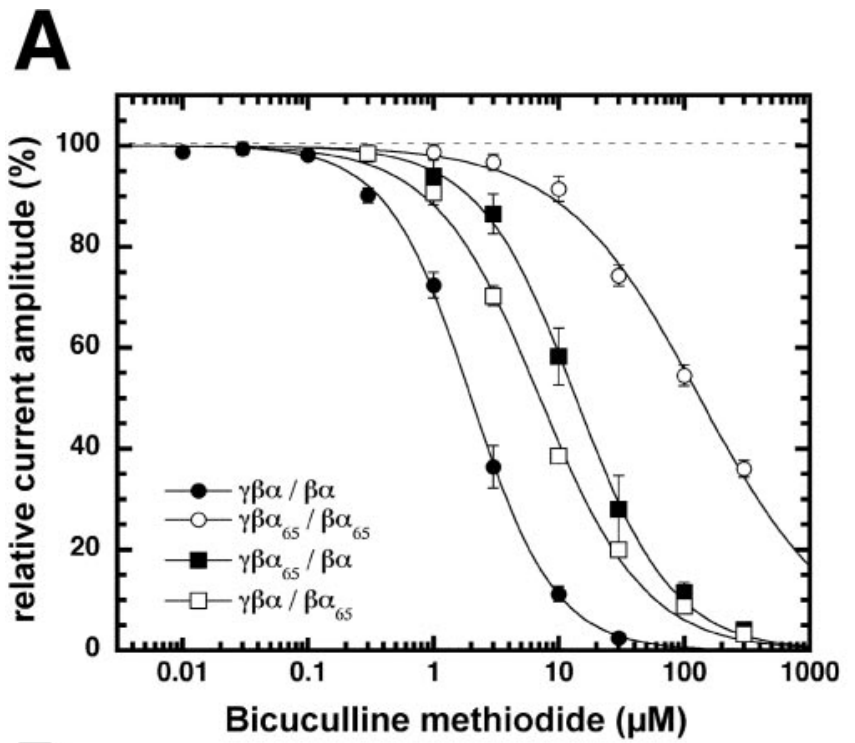

B

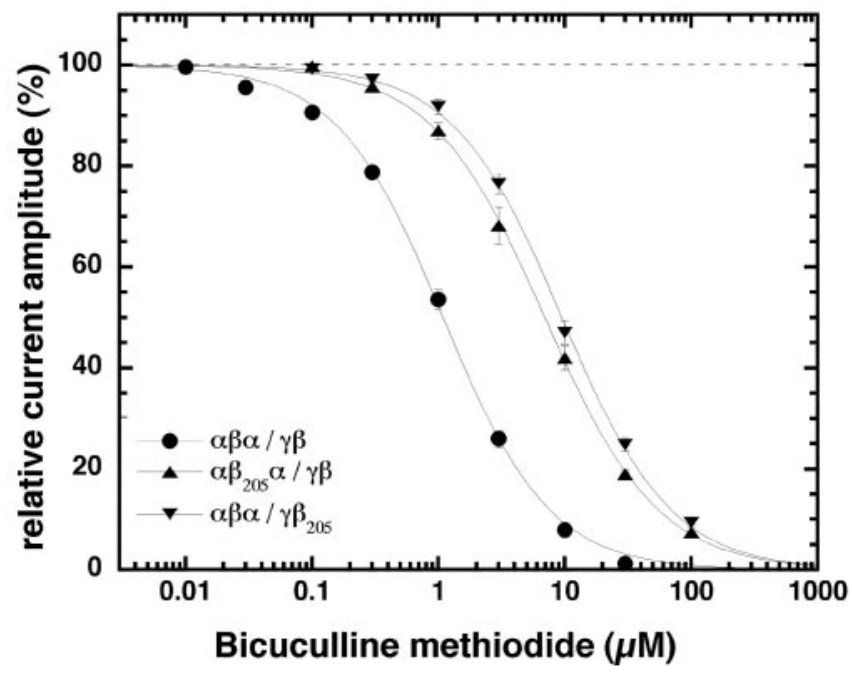

Figure 5. A, Bicuculline inhibition curves of $\gamma \beta \alpha / \beta \alpha$ (O), $\gamma \beta \alpha_{65} / \beta \alpha_{65}$ (○), $\gamma \beta \alpha_{65} / \beta \alpha(\square)$, and $\gamma \beta \alpha / \beta \alpha_{65}(\square)$ receptors. Bicuculline was applied in increasing concentrations together with a GABA concentration eliciting $9-11 \%$ of the maximal current amplitude. $B$, Bicuculline inhibition curves of $\gamma \beta \alpha / \beta \alpha(\mathbf{O}), \alpha \beta_{205} \alpha / \gamma \beta$ ( $\left.\mathbf{A}\right)$, and $\alpha \beta \alpha / \gamma \beta_{205}(\boldsymbol{\nabla})$ receptors. Mean values with SEM from four to five oocytes from two batches for each subunit combination are shown. Individual curves were normalized to the current found in the absence of bicuculline and were subsequently averaged.

\section{Diazepam responsiveness}

All receptors, $\gamma \beta \alpha / \beta \alpha, \quad \gamma \beta \alpha_{65} / \beta \alpha, \quad \gamma \beta \alpha / \beta \alpha_{65}, \quad \gamma \beta \alpha_{65} / \beta \alpha_{65}$, $\gamma \beta_{62} \alpha / \beta \alpha, \gamma \beta \alpha / \beta_{62} \alpha$, and $\gamma \beta_{62} \alpha / \beta_{62} \alpha$, were tested for stimulation of the current amplitude by $1 \mu \mathrm{M}$ diazepam at an $\mathrm{EC}_{5}$ for GABA. In all cases, the current was stimulated to $240-330 \%$ of the control amplitude (data not shown).

\section{Model}

Different models were used to analyze the experimental data. Figure 6 shows the model that was in best agreement with our findings and then used for the fit of the data. The model incorporates two binding sites for agonists and competitive antagonists, site 1 and site 2 . At least a single site has to be occupied by an agonist to produce an open state $\mathrm{AR}^{\star}, \mathrm{RA}^{\star}$, or $\mathrm{ARA}^{\star}$. Concentration-response curves, including those with nonlinked subunits, were averaged and standardized. We initially tried to fit individual curves with the equations given in Materials and Methods containing variables describing binding $\left(K_{1}, K_{2}\right)$ as well as gating $\left(L, L_{1}, L_{2}\right)$ phenomena. However, many acceptable fits were obtained. Because different curves share at least some variables, a combined Levenberg-Marquardt fit was applied to the activation curve data collected with GABA as an agonist in receptors composed of nonlinked subunits, containing linked subunits (two receptor types), mutated in site 1 (two receptor types), mutated in site 2 (two receptor types), and containing the $\alpha_{1}$ F65L mutation in both sites. Combined fitting led to a single solution. Another combined fit was applied to the data on bicuculline inhibition. Here, the fitted parameters of the activation curves were used. Results of the fits are given in the legend for Figure 6. Fitting suggested that concatenation of subunits modified gating of the channel, favoring closed channels by a factor of 4-31 (fa, fA, fg, $\mathrm{fG})$. For unmutated channels, transition into the open state is $\sim 60$ times less efficient when occupied by a single agonist molecule as compared with those occupied by two agonist molecules. Fitting also predicted that site 2 has an approximately threefold higher affinity for GABA than site 1. Data presented in Figure $4 B$ indicate a preference of site 1 for muscimol. Occupation of a single site by bicuculline keeps the channel in a closed state. Site 1 has a slight preference for bicuculline. Simulated data were obtained with the above fit results for the gating of the channel by GABA and its inhibition by bicuculline for the mutation in the $\alpha_{1}$ subunit $\alpha_{1}$ F65L (Fig. $7 A, B$ ) and the mutation in the $\beta_{2}$ subunit $\beta_{2}$ Y205S (Fig. $7 C, D$ ). The model predicts the behavior of the channels quite precisely in both cases. The coefficients ta65 and tb65, and ta205 and tb205, describing an allosteric effect on agonist and antagonist binding elicited by the mutations, was indicative of little effect in both cases of the $\alpha_{1}$ F65 mutation and an approximately twofold to fivefold effect in the case of the $\beta_{2}$ Y205S mutation.

\section{Discussion}

The $\mathrm{GABA}_{\mathrm{A}}$ receptor has been proposed to harbor two functional agonist binding sites. Occupancy of both sites greatly enhances the probability of opening the intrinsic channel. Both sites have been suggested to be located at $\beta \alpha$ subunit interfaces, but the flanking subunits of $\alpha$ are both $\beta$ in one case and $\beta$ and $\gamma$ in the other. We wanted to alter individual agonist sites by point mutation. In nonlinked receptors, only investigation of wild-type receptors, receptors containing two mutations, or mixtures of receptors containing wild-type and mutated subunits is possible. To circumvent this problem, we used concatenated subunits to dissect the functional roles of the individual binding sites.

In these concatenated subunits, we introduced mutations that affect the properties of the binding sites. We altered $\alpha \beta \alpha / \beta \gamma$ by introducing Y205S into one of the two $\beta$ subunits or both to create $\alpha \beta_{205} \alpha / \beta \gamma, \alpha \beta \alpha / \beta_{205} \gamma$, and $\alpha \beta_{205} \alpha / \beta_{205} \gamma$ channels. This point mutation has been suggested previously to abolish GABA agonist properties of the affected site (Amin and Weiss, 1993). Similarly, we introduced the point mutation F65L into one of the two $\alpha$ subunits or both in a differently concatenated channel $\gamma \beta \alpha / \beta \alpha$. The homologous residue F64 in rat $\alpha 1$ has been shown to increase the $\mathrm{IC}_{50}$ for the competitive antagonists bicuculline and SR95531 and the $\mathrm{EC}_{50}$ for the agonist GABA for channel opening (Sigel et al., 1992). The same residue was labeled in photoaffinity experiments using the agonist $\left[{ }^{3} \mathrm{H}\right]$ muscimol (Smith and Olsen, 1994). Amino acid residues including F64 probably adopt a $\beta$-sheet structure involved in agonist interaction (Boileau 
et al., 1999). Thus, the channels $\gamma \beta \alpha / \beta \alpha$, $\gamma \beta \alpha_{65} / \beta \alpha, \quad \gamma \beta \alpha / \beta \alpha_{65}$, and $\gamma \beta \alpha_{65} / \beta \alpha_{65}$ were investigated.

Introduction of the mutation $\beta_{2} \mathrm{Y} 205 \mathrm{~S}$ into one subunit resulted in very small currents as compared with the corresponding channel containing no mutation. Mutation of site 2 leads to a channel with weaker GABA sensitivity than mutation of site 1 . Introduction of the $\alpha_{1} \mathrm{~F} 65 \mathrm{~L}$ mutation in both subunits shifted the GABA concentration-response curve to $\sim 12$-fold higher concentrations. Introduction of the mutation in only one subunit, either the one flanked by two $\beta$ subunits or the one flanked by a $\beta$ and $\gamma$ subunit, caused, in either case, a very similar shift of approximately fivefold to sixfold. Our observations intuitively indicate that both sites must be occupied for the channel to open efficiently. Furthermore, we provide direct evidence for the existence of two agonist sites involving individual $\alpha$ and $\beta$ subunits.

The interaction with the agonist muscimol was also characterized. Introduction of the mutation $\beta_{2}$ Y205S indicated a higher apparent affinity of site 1 than site 2 , because mutation of site 2 led to a lower $\mathrm{EC}_{50}$ than mutation of site 1. Introduction of the mutation $\alpha_{1}$ F65L in both subunits shifted the muscimol concentration-response curve to only fourfold higher concentrations. This apparently smaller shift than that observed in the case of GABA as agonist could simply reflect a higher open tendency of the receptor with muscimol as agonist. A combined Levenberg-Marquardt fit indeed suggested a higher open tendency combined with a higher affinity of site 1 for muscimol than for site 2 .

The interaction with the competitive inhibitor bicuculline was also investigated. Except for the channels carrying the mutations in position $\beta_{2} 205$, the experiments were always performed at an agonist concentration eliciting $\sim 10 \%$ of the maximal current amplitude in the corresponding mutant. Introduction of the mutation $\beta_{2}$ Y205S led to occupancy by the agonist of the unmutated site exclusively. Mutation of either site resulted in a similar $\mathrm{IC}_{50}$. Because agonist occupancy was chosen similarly in both cases, this already indicates a similar binding affinity of bicuculline for both sites. Introduction of the mutation $\alpha_{1}$ F65L in both subunits shifted the bicuculline inhibition curve to higher concentrations; the shift was $\sim 57$-fold. Introduction of the mutation in site 2 caused a fourfold shift, and introduction in site 1 caused an eightfold shift. The relative shift between the two curves containing a single mutation is approximately twofold.

Y62 is the homologous residue on the $\beta 2$ subunit to F65 on the
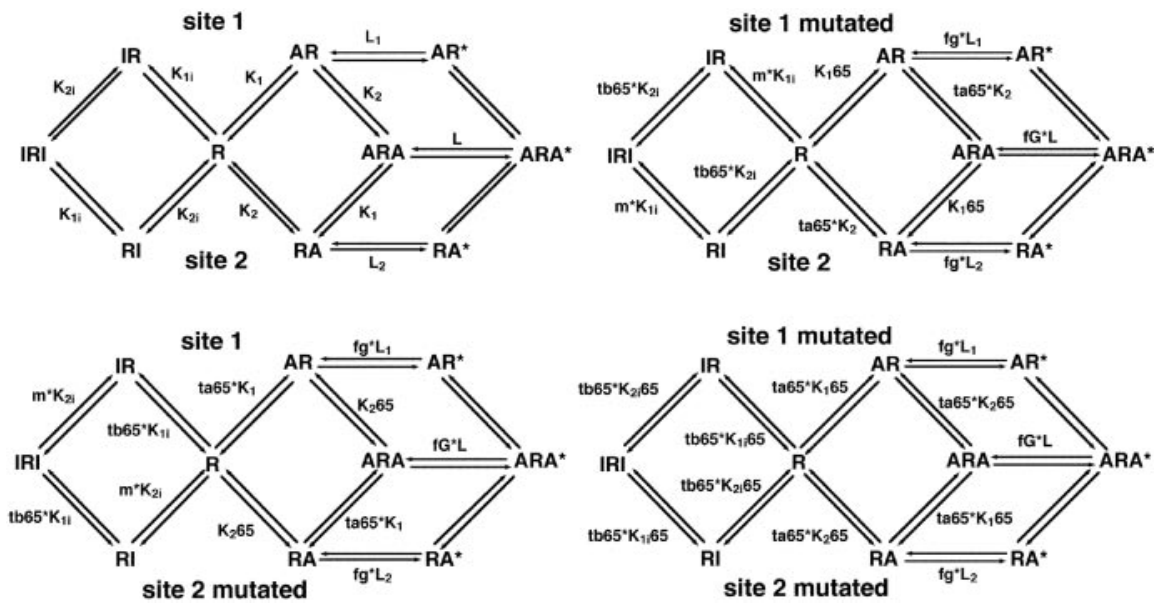

Figure 6. Model of the receptor with two agonist binding sites 1 and 2. The receptor ( $R$ ) can first bind GABA (A) to either site 1 (AR) or site 2 (RA). Analogously, the receptor can first bind bicuculline (I) to either site 1 (IR) or site 2 (RI). The receptor occupied by two agonist molecules (ARA) can isomerize to the open-state $A R A^{*}$, and the receptors occupied by a single agonist molecule can isomerize to the open-states $A R^{*}$ and $R A^{*}$. The model at the top left describes a receptor composed of loose subunits. Concentration modifies $L$ and $L_{1}$ with $f G$ and $f g$, respectively. Effects of mutation in site 1 are allosterically transferred to site 2 and vice versa (ta, agonists; tb, antagonists). Constants are taken as dissociation constants and gating constants as closed state divided by open state. Combined Levenberg-Marquardt fit gave the following estimates for the parameters: $L, 0.23 ; L_{1}, 15.3 ; L_{2}, 13.6 ; K_{1}, 128 \mu \mathrm{m}$; $K_{2}, 42 \mu \mathrm{m} ; f A, 4.5 ; f a, 8.6 ; f G, 20.4 ; f g, 31.2 ; K_{1} 65,1440 \mu \mathrm{m} ; K_{2} 65,1320 \mu \mathrm{m} ; K_{1} 205,1.3$ м; $K_{2} 205,14.9$ м; ta65, 0.84; tb65, 1.00; ta205, 4.6; tb205, 2.2; $K_{11}, 2.2 \mu \mathrm{m} ; K_{31}, 3.0 \mu \mathrm{m} ; m, 97$.
A

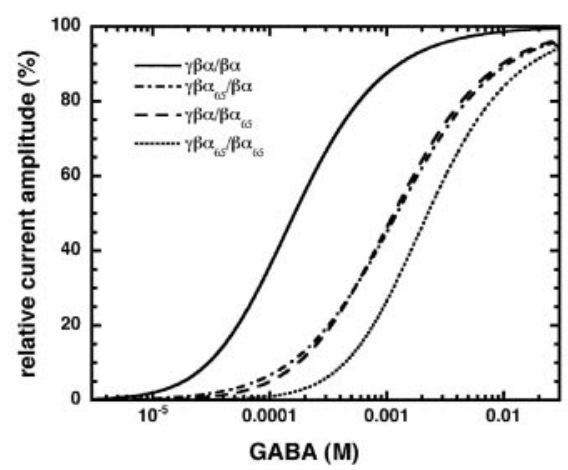

C

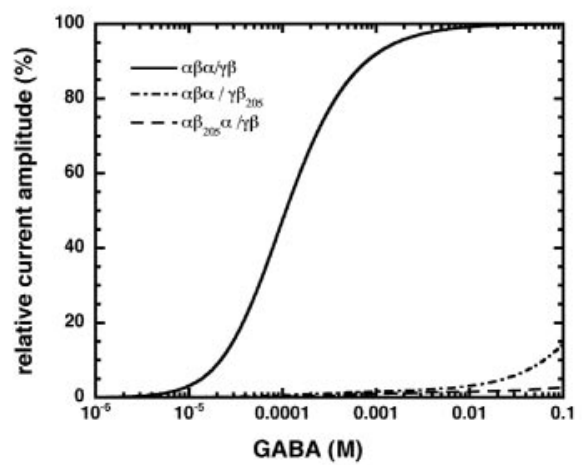

B

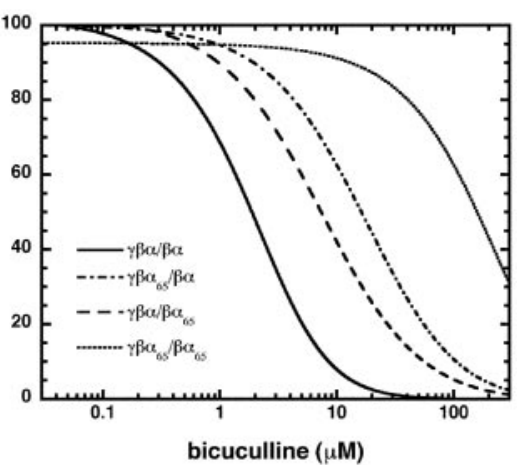

D

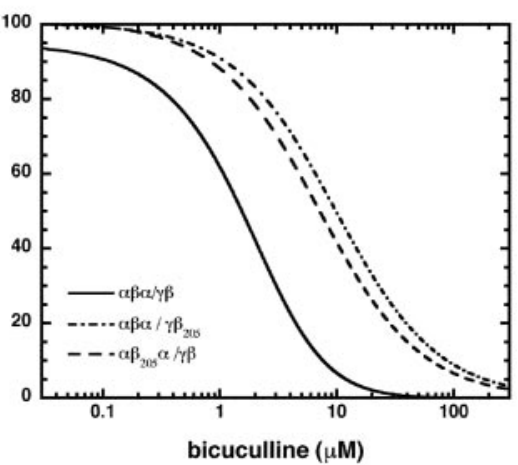

Figure 7. $A-D$, Simulation of the $G A B A$ dose-response curves $(A, C$ and bicuculline inhibition curves $(B, D)$. $A, C, \gamma \beta \alpha / \beta \alpha$, $\gamma \beta \alpha_{65} / \beta \alpha_{65}$ (sites 1 and 2 mutated), $\gamma \beta \alpha_{65} / \beta \alpha$ (site 1 mutated), and $\gamma \beta \alpha / \beta \alpha_{65}$ (site 2 mutated) receptors. $B, D, \alpha \beta \alpha / \gamma \beta$, $\alpha \beta \alpha / \gamma \beta_{205}$ (site 1 mutated), and $\alpha \beta_{205} \alpha / \gamma \beta$ (site 2 mutated) receptors. The parameters obtained in a fit are given in Figure 6 .

$\alpha 1$ subunit. Introduction of the mutation to $L$ into Y62 on the $\beta$ subunit to form $\gamma \beta_{62} \alpha / \beta_{62} \alpha$ receptors had little or no effect on the GABA concentration-response curve and on the concentration-dependent inhibition by bicuculline of currents elicited by GABA. This indicates that the homologous site to 
$\alpha_{1} \mathrm{~F} 65$ at the homologous subunit interfaces to $\beta \alpha, \alpha \beta$, and $\gamma \beta$ is not involved in GABA-mediated channel opening, and that the effect of the mutation in the $\beta$ subunit is not allosterically transmitted to the functional binding site at the $\beta \alpha$ subunit interface. The lack of an effect on the stimulation by diazepam of the current elicited by GABA indicates that the effects of both mutations are not allosterically transmitted to the binding pocket for benzodiazepines at the $\alpha \gamma$ subunit interface.

Different models were evaluated. The first envisaged channel opening receptors occupied by zero, one, or two agonist molecules (data not shown), the second only of those occupied by one or two agonist molecules (Fig. 6), and the third exclusively of those occupied by two agonist molecules (data not shown). If a significant contribution to channel opening was assumed from nonoccupied receptors or those occupied by a single agonist molecule, the GABA concentration-response curves of channels harboring a single mutation were shifted to the left. Therefore, these reactions were assumed to be relatively minor.

A combined fit for the activation curves by GABA indicated that opening of receptors occupied by two agonist molecules was characterized by an $L$ value of 0.23 . This is in good agreement with previous patch-clamp data that indicated 0.24 for this parameter (Amin and Weiss, 1993). The opening of receptors occupied by a single agonist molecule is predicted to be governed by equlibirium constants $L_{1}$ and $L_{2}$, of 15 and 14, for sites 1 and 2, respectively. Linkage of receptor subunits is predicted to affect these parameters approximately fivefold for $\alpha \beta \alpha / \gamma \beta$ and $\sim 20$ fold for $\gamma \beta \alpha / \beta \alpha$. The affinity of site 2 is predicted by this model to be approximately threefold higher for GABA than that of site 1 . Note that our conclusions may be affected by the fact that we only studied slow phenomena, and we would miss fast desensitization events occurring within the first $500 \mathrm{msec}$ after exposure to agonist in the oocyte expression system (Sigel et al., 1990). Data presented in Figure $4 B$ indicate a preference of site 1 for muscimol. The combined fit for the inhibition curves by bicuculline indicated a slightly higher apparent affinity of site 1 for bicuculline than site 2 . Note that for simplicity, our model assumes that bicuculline acts as a pure antagonist despite the fact that bicuculline action has an allosteric component (Ueno et al., 1997).

Our model only includes equilibrium constants. It is evident that the single-channel behavior of every subunit combination will have to be characterized to include rate constants and to see how the linked constructs perform in the fast time range. Natural nonconcatenated receptors have been investigated with the patch-clamp technique in cultured neurons (Macdonald et al., 1989; Weiss and Magleby, 1989; Twyman et al., 1990). Kinetic models explaining these observations have been presented. Results of experiments performed at low GABA concentrations strongly suggested that a single bound molecule of GABA inefficiently opens the receptor with brief open times and noncomplex bursts. The majority of channel openings was interpreted as reflecting the doubly occupied receptor. In the above cases, analysis was complicated by the presence of multiple $\mathrm{GABA}_{\mathrm{A}}$ receptor types in a single cell. However, a less comprehensive analysis of recombinant $\alpha_{1} \beta_{1} \gamma_{2 S} \mathrm{GABA}_{\mathrm{A}}$ receptors indicated a similar kinetic behavior (Angelotti and Macdonald, 1993). In summary, the similarity of our experiments and model supports the intuitive suggestion that both sites must be occupied for the channel to open efficiently, a fact predicted by single-channel kinetic analysis, and that occupancy of a single site by bicuculline is sufficient to prevent channel opening.

How can it be explained that the two sites display different properties for agonist and similar properties for competitive an-

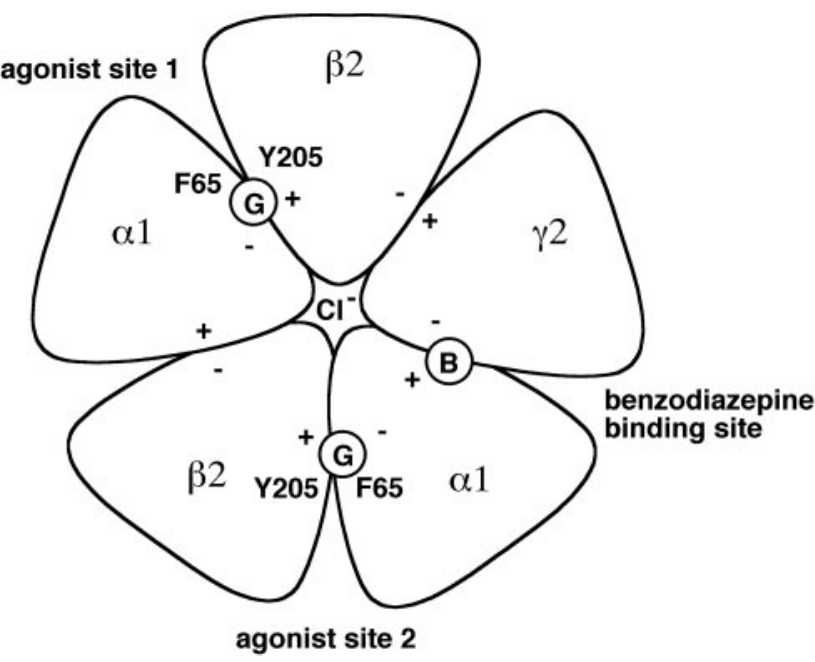

Figure 8. Schematic representation of the $\mathrm{GABA}_{\mathrm{A}}$ receptor showing the two functional agonist sites $(G)$ and the benzodiazepine binding site $(B)$. Agonist site 2 has a preference for the agonist GABA, and site 1 has a preference for muscimol and a slight preference for the antagonist bicuculline.

tagonist interaction? Each agonist or antagonist molecule contacts several atoms in the receptor. The fact that both sites are located at the $\beta \alpha$ subunit interface but display subtly different properties may be explained by a subtly different conformation of the two sites, depending on the nature of the flanking subunits (Fig. 8). Note that the published structure of the acetylcholine binding protein has five identical subunits (Brejc et al., 2001), and the atom coordinates of the recently proposed model by Cromer et al. (2002) are not available, such that our predicted structural differences of the two binding sites cannot be visualized.

Analogously to the methods presented here, the role of any individual site located on an $\alpha$ or $\beta$ subunit may be studied, which was impossible thus far because there were always two sites on the two subunits affected by a mutation in $2 \alpha 2 \beta 1 \gamma$ GABA $_{\mathrm{A}}$ receptors. The method enables targeted introduction of a mutation in only one defined subunit. Because the $\mathrm{GABA}_{\mathrm{A}}$ receptor belongs to a superfamily of ligand-gated ion channels, procedures described here are applicable to the entire family of ligandgated channels comprising nicotinic acetylcholine, glycine, and $5 \mathrm{HT}_{3}$ receptors.

\section{References}

Amin J, Weiss DS (1993) GABA $_{\mathrm{A}}$ receptor needs two homologous domains of the $\beta$-subunit for activation by GABA but not by pentobarbital. Nature 366:565-569.

Amin J, Brooks-Kayal A, Weiss DS (1997) Two tyrosine residues on the $\alpha$ subunit are crucial for benzodiazepine binding and allosteric modulation of gamma-aminobutyric acidA receptors. Mol Pharmacol 51:833-841.

Angelotti TP, Macdonald RL (1993) Assembly of GABA $_{\mathrm{A}}$ receptor subunits: $\alpha_{1} \beta_{1}$ and $\alpha_{1} \beta_{1} \gamma_{2 \mathrm{~S}}$ subunits produce unique ion channels with dissimilar single-channel properties. J Neurosci 13:1429-1440.

Backus KH, Arigoni M, Drescher U, Scheurer L, Malherbe P, Möhler H, Benson JA (1993) Stoichiometry of a recombinant $\mathrm{GABA}_{\mathrm{A}}$ receptor deduced from mutation-induced rectification. NeuroReport 5:285-288.

Barnard EA, Skolnick P, Olsen RW, Möhler H, Sieghart W, Biggio G, Braestrup C, Bateson AN, Langer SZ (1998) International union of pharmacology. XV. Subtypes of gamma-aminobutyric acidA receptors: classification on the basis of subunit structure and receptor function. Pharmacol Rev 50:291-313.

Baumann SW, Baur R, Sigel E (2001) Subunit arrangement of gammaaminobutyric acid type A receptors. J Biol Chem 276:36275-36280.

Baumann SW, Baur R, Sigel E (2002) Forced subunit assembly in $\alpha 1 \beta 2 \gamma 2$ 
$\mathrm{GABA}_{\mathrm{A}}$ receptors: insight into the absolute arrangement. J Biol Chem 277:46020-46025.

Benke D, Fritschy JM, Trzeciak A, Bannwarth W, Möhler H (1994) Distribution, prevalence, and drug binding profile of gamma-aminobutyric acid type A receptor subtypes differing in the $\beta$-subunit variant. J Biol Chem 269:27100-27107.

Boileau AJ, Evers AR, Davis AF, Czajkowski C (1999) Mapping the agonist binding site of the $\mathrm{GABA}_{\mathrm{A}}$ receptor: evidence for a $\beta$-strand. J Neurosci 19:4847-4854.

Boileau AJ, Baur R, Sharkey LM, Sigel E, Czajkowski C (2002) The relative amount of cRNA coding for $\gamma 2$ subunits affects stimulation by benzodiazepines in $\mathrm{GABA}_{\mathrm{A}}$ receptors expressed in Xenopus oocytes. Neuropharmacology 43:695-700.

Brejc K, van Dijk WJ, Klaassen RV, Schuurmans M, van Der Oost J, Smit AB, Sixma TK (2001) Crystal structure of an ACh-binding protein reveals the ligand-binding domain of nicotinic receptors. Nature 411:269-276.

Buhr A, Sigel E (1997) A point mutation in the $\gamma 2$ subunit of gammaaminobutyric acid type A receptors results in altered benzodiazepine binding site specificity. Proc Natl Acad Sci USA 94:8824-8829.

Buhr A, Baur R, Sigel E (1997a) Subtle changes in residue 77 of the $\gamma$ subunit of $\alpha 1 \beta 2 \gamma 2 \mathrm{GABA}_{\mathrm{A}}$ receptors drastically alter the affinity for ligands of the benzodiazepine binding site. J Biol Chem 272:11799-11804.

Buhr A, Schaerer MT, Baur R, Sigel E (1997b) Residues at positions 206 and 209 of the $\alpha 1$ subunit of gamma-aminobutyric acidA receptors influence affinities for benzodiazepine binding site ligands. Mol Pharmacol 52:676-682.

Chang Y, Wang R, Barot S, Weiss DS (1996) Stoichiometry of a recombinant $\mathrm{GABA}_{\mathrm{A}}$ receptor. J Neurosci 16:5415-5424.

Cromer BA, Morton CJ, Parker MW (2002) Anxiety over GABA(A) receptor structure relieved by AChBP. Trends Biochem Sci 27:280-287.

Davies PA, Hanna MC, Hales TG, Kirkness EF (1997) Insensitivity to anaesthetic agents conferred by a class of GABA(A) receptor subunit. Nature 385:820-823.

Edelstein SJ, Schaad O, Changeux JP (1997) Single binding versus single channel recordings: a new approach to study ionotropic receptors. Biochemistry 36:13755-13760.

Ewert M, Shivers BD, Lüddens H, Möhler H, Seeburg PH (1990) Subunit selectivity and epitope characterization of $\mathrm{mAbs}$ directed against the $\mathrm{GABA}_{\mathrm{A}} /$ benzodiazepine receptor. J Cell Biol 110:2043-2048.

Farrar SJ, Whiting PJ, Bonnert TP, McKernan RM (1999) Stoichiometry of a ligand-gated ion channel determined by fluorescence energy transfer. J Biol Chem 274:10100-10104.

Häring P, Stähli C, Schoch P, Takacs B, Staehelin T, Möhler H (1985) Monoclonal antibodies reveal structural homogeneity of gamma-aminobutyricacid/benzodiazepine receptors in different brain areas. Proc Natl Acad Sci USA 82:4837-4841.

Hedblom E, Kirkness EF (1997) A novel class of $\mathrm{GABA}_{\mathrm{A}}$ receptor subunit in tissues of the reproductive system. J Biol Chem 272:15346-15350.

Kuhn FJ, Greeff NG (1999) Movement of voltage sensor S4 in domain 4 is tightly coupled to sodium channel fast inactivation and gating charge immobilization. J Gen Physiol 114:167-183.

Laemmli UK (1970) Cleavage of structural proteins during the assembly of the head of bacteriophage T4. Nature 227:680-685.

Laurie DJ, Seeburg PH, Wisden W (1992) The distribution of $13 \mathrm{GABA}_{\mathrm{A}}$ receptor subunit mRNAs in the rat brain. II. Olfactory bulb and cerebellum. J Neurosci 12:1063-1076.

Macdonald RL, Olsen RW (1994) $\mathrm{GABA}_{\mathrm{A}}$ receptor channels. Annu Rev Neurosci 17:569-602.

Macdonald RL, Rogers CJ, Twyman RE (1989) Kinetic properties of the $\mathrm{GABA}_{\mathrm{A}}$ receptor main conductance state of mouse spinal cord neurones in culture. J Physiol (Lond) 410:479-499.

Martinez KL, Corringer PJ, Edelstein SJ, Changeux JP, Mérola F (2000) Structural differences in the two agonist binding sites of the Torpedo nicotinic acetylcholine receptor revealed by time-resolved fluorescence spectroscopy. Biochemistry 39:6979-6990.

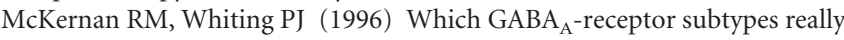
occur in the brain? Trends Neurosci 19:139-143.

Newell JG, Davies M, Bateson AN, Dunn SM (2000) ) Tyrosine 62 of the gamma-aminobutyric acid type A receptor beta 2 subunit is an important determinant of high affinity agonist binding. J Biol Chem 275:14198-14204.

Neubig RR, Cohen JB (1979) Equilibrium binding of $\left[{ }^{3} \mathrm{H}\right]$ tubocurarine and $\left[{ }^{3} \mathrm{H}\right]$ acetylcholine by Torpedo postsynaptic membranes: stoichiometry and ligand interactions. Biochemistry 18:5464-5475.

Rabow LE, Russek SJ, Farb DH (1995) From ion currents to genomic analysis: recent advances in $\mathrm{GABA}_{\mathrm{A}}$ receptor research. Synapse 21:189-274.

Sigel E (1987) Properties of single sodium channels translated by Xenopus oocytes after injection with messenger ribonucleic acid. J Physiol (Lond) 386:73-90.

Sigel E, Buhr A (1997) The benzodiazepine binding site of $\mathrm{GABA}_{\mathrm{A}}$ receptors. Trends Pharmacol Sci 18:425-429.

Sigel E, Stephenson FA, Mamalaki C, Barnard EA (1983) A gammaaminobutyric acid/benzodiazepine receptor complex of bovine cerebral cortex. J Biol Chem 258:6965-6971.

Sigel E, Baur R, Trube G, Möhler H, Malherbe P (1990) The effect of subunit composition of rat brain $\mathrm{GABA}_{\mathrm{A}}$ receptors on channel function. Neuron 5:703-711.

Sigel E, Baur R, Kellenberger S, Malherbe P (1992) Point mutations affecting antagonist affinity and agonist dependent gating of $\mathrm{GABA}_{\mathrm{A}}$ receptor channels. EMBO J 11:2017-2023.

Smith GB, Olsen RW (1994) Identification of a $\left[{ }^{3} \mathrm{H}\right]$ muscimol photoaffinity substrate in the bovine gamma-aminobutyric acidA receptor $\alpha$ subunit. J Biol Chem 269:20380-20387.

Teissere JA, Czajkowski C (2001) A $\beta$-strand in the $\gamma 2$ subunit lines the benzodiazepine binding site of the $\mathrm{GABA}_{\mathrm{A}}$ receptor: structural rearrangements detected during channel gating. J Neurosci 21:4977-4986.

Tretter V, Ehya N, Fuchs K, Sieghart W (1997) Stoichiometry and assembly of a recombinant $\mathrm{GABA}_{\mathrm{A}}$ receptor subtype. J Neurosci 17:2728-2737.

Towbin H, Staehelin T, Gordon J (1979) Electrophoretic transfer of proteins from polyacrylamide gels to nitrocellulose sheets: procedure and some applications. Proc Natl Acad Sci USA 76:4350-4354.

Twyman RE, Rogers CJ, Macdonald RL (1990) Intraburst kinetic properties of the GABAA receptor main conductance state of mouse spinal cord neurones in culture. J Physiol (Lond) 423:193-220.

Ueno S, Bracamontes J, Zorumski C, Weiss DS, Steinbach JH (1997) Bicuculline and gabazine are allosteric inhibitors of channel opening of the $\mathrm{GABA}_{\mathrm{A}}$ receptor. J Neurosci 17:625-634.

Weiss DS, Magleby KL (1989) Gating scheme for single GABA-activated $\mathrm{Cl}$ - channels determined from stability plots, dwell-time distributions, and adjacent-interval durations. J Neurosci 9:1314-1324.

Westh-Hansen SE, Rasmussen PB, Hastrup S, Nabekura J, Noguchi K, Akaike N, Witt MR, Nielsen M (1997) Decreased agonist sensitivity of human GABA(A) receptors by an amino acid variant, isoleucine to valine, in the $\alpha 1$ subunit. Eur J Pharmacol 329:253-257.

Whiting PJ, McAllister G, Vassilatis D, Bonnert TP, Heavens RP, Smith DW, Hewson L, O'Donnell R, Rigby MR, Sirinathsinghji DJ, Marshall G, Thompson SA, Wafford KA, Vasilatis D (1997) Neuronally restricted RNA splicing regulates the expression of a novel $\mathrm{GABA}_{\mathrm{A}}$ receptor subunit conferring atypical functional properties. J Neurosci 17:5027-5037.

Whiting PJ, Bonnert TP, McKernan RM, Farrar S, Le Bourdelles B, Heavens RP, Smith DW, Hewson L, Rigby MR, Sirinathsinghji DJ, Thompson SA, Wafford KA (1999) Molecular and functional diversity of the expanding GABA-A receptor gene family. Ann NY Acad Sci 868:645-653.

Wieland HA, Luddens H, Seeburg PH (1992) A single histidine in $\mathrm{GABA}_{A}$ receptors is essential for benzodiazepine agonist binding. J Biol Chem 267:1426-1429. 